\title{
RESENHAS
}

FERES JÚNIOR, João. 2005. A história do conceito de “Latin America” nos Estados Unidos. Bauru : USC.

\section{LATIN AMERICA: WHAT DOES IT MEAN?}

\author{
Daniel Jatobá
}

"The concept is not merely a sign for, but also a factor in, political or social groupings"1 (Reinhart Koselleck).

\begin{abstract}
"A Latin America tem sido definida no inglês americano, tanto na linguagem comum quanto nos textos especializados, como o oposto de uma auto-imagem glorificada de America" (João Feres Júnior).
\end{abstract}

Quais são os significados que vêm à tona quando o termo Latin America é empregado, no inglês norteamericano? Feres Júnior analisa a história do conceito de Latin America, expressão fortemente presente tanto na linguagem cotidiana como nos discursos científicos nos Estados Unidos. Com uma abordagem crítica, o autor busca demonstrar que as percepções do Outro servem para, em primeiro lugar, reforçar a própria identidade coletiva norte-americana; além disso, são utilizadas para legitimar as políticas externas dos Estados Unidos frente aos demais países da região, cuja história é marcada por intervenções militares e políticas.

Para os interessados em análise do discurso, tem-se ao alcance com $A$ história do conceito de "Latin America" nos Estados Unidos, de João Feres Júnior, um livro que apresenta resultados substantivos interessantes, comentados adiante, e, do ponto de vista metodológico, um instrumental analítico que "pode ser aplicado ao estudo de outros conceitos assimétricos, assim como à identificação da negação do reconhecimento através da linguagem, ou seja, como uma modalidade de análise do discurso" (FERES JÚNIOR, 2005, p. 279). O que o autor sugere é que as ferramentas metodológicas que utiliza poderiam ser usadas para analisar outras oposições assimétricas, como é o caso da contradição entre Latin America e America nos Estados Unidos, o primeiro conceito representando um conjunto de povos situados ao Sul de sua fronteira com o México, enquanto o conceito de America é associado à própria identidade coletiva. Nessa pesquisa, realizada pelo autor por ocasião de sua tese de doutorado na City University of New York, foram analisados os discursos comum e sócio-científico; no caso da primeira modalidade discursiva, elaborados desde o século XIX ao atual, enquanto os discursos acadêmicos escolhidos foram produzidos a partir da institucionalização e consolidação dos assim chamados Latin American Studies.

Aqueles que se interessam por relações internacionais encontrarão um estudo crítico que tangencia um problema bastante discutido atualmente neste campo, o papel das idéias na política internacional e, mais especificamente, a questão das implicações práticas da definição da alteridade em termos do oposto de uma auto-identidade enaltecida, isto é, uma definição do Outro por meio da vinculação de significados que rebaixam seu valor. Tem-se um terreno fértil para o estudo do papel da identidade nas relações internacionais, especialmente no que diz respeito às relações dos Estados Unidos com os países da Latin America; em uma expressão não contida na obra, mas sugerida pelo autor, não é um livro de relações internacionais, mas tem muito a ver.

O autor investiga os significados atribuídos ao conceito Latin America no inglês norte-americano e, ao penetrar no seu campo semântico, identifica a presença de significados desrespeitosos. Nos dias de hoje, quando os termos empregados para denominar o Outro vêm sendo objeto de revisão crítica, especialmente na sociedade norte-americana, onde a voga do multiculturalismo e do politicamente correto puseram na berlinda

1 “O conceito não é meramente um signo para, mas é também um fator nos agrupamentos políticos ou sociais" (nota do revisor). 
expressões como nigger (usada para afro-americanos), chink (chineses), kike (judeus), deigo, guido ou wap (italianos), é instigante perceber como algumas denominações étnicas, como é o caso de Latin America, escaparam dessa vaga revisionista, pelo fato de não serem explicitamente insultantes. Há um movimento de avaliação crítica de algumas das expressões utilizadas para identificar povos, culturas e regiões do mundo; apesar de defender-se a eliminação dessas expressões do uso cotidiano da língua inglesa nos Estados Unidos, o mesmo não ocorre com a expressão estudada.

Diferentemente de outros conceitos utilizados para designar o Outro, em que há um caráter claramente pejorativo, à primeira vista "Latin America" poderia escapar ileso do teste do politicamente correto. Para o bem da verdade, a obra de Feres Júnior analisa a história do conceito nos Estados Unidos e argumenta que "o conceito de Latin America tem sido de fato um instrumento de representação distorcida daqueles que os americanos percebem como Latin Americans" (idem, p. 9), o que contribui para o tratamento assimétrico historicamente conferido aos povos oriundos dessa região, seja para os que em suas terras permanecem, seja para os indivíduos e famílias que fizeram a escolha de viver em território norte-americano.

Como já indicamos, no livro são examinados os significados atribuídos ao termo nos Estados Unidos na linguagem comum e nos discursos produzidos por cientistas sociais, como historiadores, sociólogos e cientistas políticos. A análise do discurso empreendida pelo autor conjuga dois eixos, um diacrônico, pelo qual se analisa a evolução histórica do conceito de Latin America nos Estados Unidos, desde os primórdios de seu aparecimento, ainda no século XIX, até os dias atuais; a esse eixo é adicionado outro, sincrônico, com a análise dos dois campos discursivos mencionados. No caso da primeira modalidade discursiva, o autor baseia-se em discursos e textos de políticos proeminentes, jornalistas e intelectuais, todos norte-americanos. Quanto aos textos sócio-científicos analisados, o autor selecionou quatro abordagens teóricas que se desenvolveram no âmbito dos Latin American Studies, que se consolidaram na academia norte-americana a partir dos anos 1960, logo após a Revolução Cubana e em meio à preocupação do governo com a "ameaça comunista" na região. Na busca dos significados historicamente associados à Latin America nas Ciências Sociais, as fontes semânticas são buscadas nos discursos da teoria da modernização, da literatura da estabilidade política, dos estudos da dependência e do corporativismo.

O autor adota uma abordagem crítica do seu objeto, se é correto afirmar que a crítica é uma atitude opcional dos cientistas sociais, quando quiçá seja melhor tomá-la como um imperativo que se lhes impõe. De qualquer forma, o fato é que ele demonstra perspicácia analítica ao identificar, na evolução histórica de um conceito hoje tão presente na sociedade norte-americana, a presença de significados pejorativos ou insultuosos atribuídos ao termo estudado. A abordagem crítica, descrita por Feres Júnior como um projeto de desvendamento do mundo presente com o propósito de transformá-lo, é realizada a partir da perspectiva da teoria do reconhecimento, cujo uso é justificado pela preocupação do livro com "a questão do significado moral da definição do Outro como mera negação da auto-imagem de um Eu coletivo" (idem, p. 23).

Esse campo teórico, um dos mais importantes da teoria social contemporânea, vem sendo consolidado ao longo dos últimos três lustros, desde a publicação do texto seminal de Charles Taylor, que em 1992 publicou The Politics of Recognition ${ }^{2}$. Ainda que a formulação original da idéia de reconhecimento seja de autoria do filósofo alemão Georg W. Hegel, na Fenomenologia do espirito, foi somente nos anos 1990 que o tema adquiriu relevância em comunidades acadêmicas de todo o mundo.

No caso de Taylor, sua preocupação é com a temática do multiculturalismo. Seu texto é escrito em um contexto histórico em que as principais lutas em favor de reconhecimento baseiam-se em critérios culturais, como movimentos de gênero, de livre opção sexual, de minorias raciais ou étnicas, o que gera um descompasso com o princípio fundamental da democracia liberal, qual seja, o da extensão universal de direitos, liberdades e garantias. Para ele, as sociedades organizadas em torno de democracias liberais possuem um limite normativo para atender as demandas pelo reconhecimento baseadas na diferença cultural.

Segundo Feres Júnior, Taylor foi um pioneiro da literatura do reconhecimento, mas "o trabalho de Axel Honneth é sem dúvida o mais sistemático e de maior estofo filosófico" (idem, p. 32). Resumidamente, o projeto de Honneth (1995) situa-se na tradição que enfatiza a luta pelo estabelecimento de relações de reconhecimento

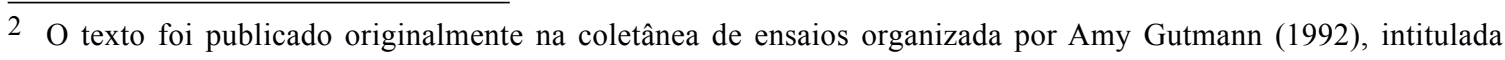
Multiculturalism: Examining the Politics of Recognition. 
mútuo como uma condição prévia para a auto-realização. Por meio da reconstrução da linha argumentativa hegeliana, Honneth propõe uma tipologia das formas de reconhecimento, eqüidistante de uma categorização prévia das formas de desrespeito: amor versus maus-tratos físicos, reconhecimento da cidadania versus negação de direitos e respeito versus depreciação do estilo de vida individual ou grupal.

No entanto, nenhum desses autores enfrentou a questão do uso da linguagem na atribuição ou negação do reconhecimento. Por essa razão, coube a Feres Júnior desenvolver uma tipologia das formas de desrespeito, com base nos três núcleos fundamentais em torno dos quais os significados atribuídos ao Outro são concentrados: resulta uma interessante tipologia que, além de servir à análise por ele encampada, pode ser replicada por outros estudiosos que tenham preocupações semelhantes.

A construção da tipologia das formas de desrespeito é realizada a partir da noção de "contraconceito assimétrico", de Reinhart Koselleck (1985 [1979] $)^{3}$. O historiador alemão trabalhou com os conceitos usados por grupos como meio de negar reconhecimento a outros; segundo ele, essas formações conceituais ocorrem na forma de pares de contraconceitos assimétricos. Cada um dos pares analisados por Koselleck é constituído por um conceito positivo, utilizado para nomear o próprio grupo, ou seja, a própria identidade coletiva, e um conceito negativo, atribuído ao Outro, que embora sinta que o conceito é a ele dirigido, não se sente propriamente reconhecido nele. Nos termos de Feres Júnior, tem-se "um problema capital de reconhecimento, pois o Outro experimenta a definição que lhe é impingida como ofensa, insulto e/ou privação" (idem, p. 38). Koselleck analisou, entre outras oposições assimétricas, os pares conceituais heleno-bárbaro, cristão-pagão e arianonão-ariano; para ele, a eficácia das classificações mútuas é intensificada historicamente quando aplicadas a grupos. Esse fato, por si só, torna o estudo das conceituações que dividem as coletividades em "nós" e "eles" de extrema relevância para os cientistas sociais.

Com base nos pares de conceitos estudados pelo historiador, Feres Júnior desenvolve uma tipologia própria, como dito, em que há três oposições assimétricas fundamentais. Primeiramente, tem-se a oposição assimétrica cultural, pela qual o Outro é descrito "em termos da negação ou falta de instituições, costumes e práticas atribuídas ao Eu coletivo" (idem, p. 42). Em segundo lugar, tem-se a oposição assimétrica temporal, definida como aquela que atribui ao Outro características de atraso no desenvolvimento material ou moral; por fim, a terceira categoria de desrespeito é manifestada pelo uso de conceitos que traduzem oposições assimétricas raciais, isto é, centradas na atribuição de determinadas características ao Outro em razão de componentes sobretudo biológicos, expressos por referências a aspectos físicos, fisionômicos e psicológicos. Apesar da categorização das formas de desrespeito, muitas vezes as diferentes formas de oposição assimétrica manifestam-se no plano discursivo articuladas em um mesmo conceito, pela capacidade que possuem de denotar mais de uma forma de desrespeito simultaneamente. Para expressar esse fenômeno, o autor constrói a categoria denominada "traduzibilidade das formas de oposição assimétrica", "[...] definida como a propriedade pela qual certas expressões lingüísticas são capazes de denotar mais de uma forma de desrespeito. Vocabulários usados na descrição de uma determinada forma de oposição assimétrica, não raro, têm a capacidade de sugerir outras. Por exemplo, a palavra 'temperamento' tem matizes culturais e raciais; categorias sócio-científicas como 'patriarcalismo' e 'feudalismo' têm nuanças culturais e temporais" (idem, p. 47).

Ao analisar a evolução histórica do conceito nos EUA, o que se vislumbra é uma assimetria fundamental entre a representação da própria identidade coletiva norte-americana e a imagem do Outro. Em outros termos, as características atribuídas aos Latin Americans são o oposto daquelas percebidas como constitutivas da própria identidade coletiva. É interessante notar que os significados altamente pejorativos ou insultuosos atribuídos ao conceito de Latin America na linguagem cotidiana são reproduzidos pelos discursos especializados produzidos pelas Ciências Sociais nos Estados Unidos, fortemente marcadas pelo paradigma da suposta neutralidade valorativa de suas interpretações, ainda que o conceito tenha sofrido algumas alterações semânticas, como a ocultação da oposição assimétrica racial.

Historicamente, o conceito de Latin America foi utilizado pela primeira vez em língua inglesa em 1890, em um documento de autoria do Presidente norte-americano Benjamin Harrison, denominado Reciprocity Treaties

\footnotetext{
3 Essa noção foi desenvolvida na obra Futures Past, uma reunião de ensaios publicados entre 1965 e 1977, cuja leitura fornece uma boa visão geral do projeto intelectual da história conceitual alemã (Begriffsgeschichte), desenvolvida junto a Otto Brunner e Werner Conze - sobretudo o último.
} 
with Latin America. Na verdade, tratava-se de uma tradução do termo francês Amérique Latine ou do espanhol América Latina, cunhados pouco tempo antes - segundo Feres Júnior, não há qualquer registro anterior ao ano de 1856. É interessante notar que seu surgimento está relacionado à política internacional, uma vez que o termo foi elaborado no contexto da doutrina do panlatinismo, durante o reinado de Napoleão III (1851-1870), segundo a qual se defendia a unidade dos povos de raça latina: "para os ideólogos do panlatinismo, a França estaria na vanguarda da raça latina e, portanto, deveria liderar as nações irmãs menos favorecidas à reconquista de um papel de proeminência na história da civilização humana - papel esse perdido para os povos germânicos e anglo-saxões" (idem, p. 52).

No caso específico dos Estados Unidos, Feres Júnior identifica uma pré-história do conceito de Latin America, representada pela expressão Spanish America, utilizada freqüentemente por políticos durante o século XIX. Ainda que houvesse pouco contato com os povos da região, o termo era associado a significados pejorativos, em uma extensão do sentimento anti-espanhol que florescera no século XVI na Grã-Bretanha e que também foi estendido para as terras norte-americanas. As características atribuídas por políticos norte-americanos aos povos Spanish Americans claramente apontam para a construção de oposições culturais assimétricas, que contrapõem à identidade do Outro uma auto-imagem glorificada: "Cada uma das características negativas atribuídas a eles, dominados por clérigos (católicos), indolentes, ignorantes, supersticiosos, incapazes de se esforçar e desprovidos de iniciativa, correspondem univocamente a uma característica positiva da auto-imagem americana: protestante (portanto, anticatólico), trabalhador, educado, racional, industrioso e provido de espírito de iniciativa" (idem, p. 59).

Essas características a que o autor refere-se são extraídas de discursos de políticos proeminentes, como Thomas Jefferson, John Adams, seu filho John Quincy Adams, ou Beaufort Watts. Os dois últimos deram um passo adiante, no sentido de realizar traduções raciais das oposições culturais assimétricas: o primeiro compara os espanhóis, "vadios, sujos e malvados", a uma vara de porcos e estende essas características aos Spanish Americans, enquanto Watts compara um "típico colombiano" a um cão subserviente. São apenas alguns dos muitos exemplos encontrados pelo autor que indicam os significados pejorativos e insultuosos atrelados à idéia de Spanish America, expressão que precedeu Latin America e que a esta legou alguns de seus significados mais aviltantes.

O aumento do contato com os povos das Américas Central e do Sul não alterou substancialmente o conteúdo semântico, mas aprofundou a assimetria construída entre a própria identidade e a alteridade considerada como um conjunto indistinto. Por motivos políticos, a inferioridade racial, o atraso histórico e a distância cultural do Outro foram utilizadas com freqüência durante a expansão para o Oeste, quando os Estados Unidos guerrearam contra o México e anexaram o atual estado do Texas (1845). Nesse contexto, prevalecia a Doutrina Monroe, como ficou conhecida a declaração de James Monroe em 1822, que destinava para o futuro "a América para os americanos". Em suma, o conteúdo dessa doutrina previa o não-envolvimento dos Estados Unidos nas complicações políticas européias, enquanto as potências européias eram instadas a não exercer seu princípio de intervenção nos assuntos americanos.

A inferioridade do Outro servia para justificar as ações expansionistas em direção à América Central; com a Guerra Hispano-americana (1898), travada contra uma Espanha "monárquica e colonialista", os Estados Unidos saíram com o domínio sobre as ex-colônias espanholas no Caribe (Cuba - tornada independente e depois protetorado norte-americano, em 1891, e finalmente colônia em 1901 - e Porto Rico) e no Pacífico (Ilhas Filipinas e Guam). Os Estados Unidos deixavam de lado a tradição anti-imperialista do século XIX para engajaremse em conquistas coloniais - processo que se completou com a anexação do Havaí, também em 1898, e o apoio à independência do Panamá, em 1903, contra a Colômbia, pelo interesse de dominar o canal que liga os dois oceanos que banham as Américas. Gradativamente, o país afastou-se da tradição isolacionista para exercer uma política externa mais afirmativa, simbolizada pelo lema do Presidente Theodore Roosevelt (1901-1909): "speak softly and carry a big stick" - ou, em português claro, "fale suavemente e carregue um grande porrete" (DÖPCKE, 2001). Esse também foi o momento em que a expressão Latin America passou a ser utilizada com maior freqüência no inglês norte-americano.

Ao mesmo tempo, na passagem para o século XX, assistiu-se ao ressurgimento da doutrina do Destino Manifesto no debate público norte-americano antes da I Guerra Mundial e também nas discussões que se seguiram à vitória dos Estados Unidos nesse conflito. A raça anglófona e teutônica dos norte-americanos era afirmada como superior às demais; a civilização carregada por eles deveria prevalecer sobre a barbárie e a 
selvageria características do Outro e a imaturidade, senilidade ou decrepitude do Outro denotavam um sentido de atraso histórico - a um só tempo, são encontradas as oposições assimétricas racial, cultural e temporal.

Da análise da história do conceito na linguagem comum, o autor constata que existe um alto grau de continuidade histórica e que o campo semântico de Latin America é estruturado pelas três oposições assimétricas. A tarefa seguinte é um exercício de comparação com a construção do conceito por meio do discurso sócio-científico, pois "somente estudando a Latin America nesses dois contextos diversos e historicamente sucessivos é que conseguiremos compreender as continuidades e rupturas introduzidas pelo discurso sócio-científico, além de obter insights sobre a relação entre o labor das Ciências Sociais e o planejamento de políticas governamentais" (FERES JÚNIOR, 2005, p. 79-80).

Quais são os resultados substantivos da análise do discurso elaborado por cientistas sociais nos Estados Unidos? Antes de apresentar algo dos interessantes resultados substantivos obtidos pela investigação, convém esclarecer quais foram as fontes textuais analisadas, especificada no primeiro dos quatro capítulos sobre os discursos sócio-científicos: "obras que teorizam explicitamente sobre a Latin America, isto é, trabalhos nos quais o principal objeto de investigação pela Latin America como um todo" (idem, p. 80). Cada um desses capítulos oferece os resultados da análise de uma perspectiva teórica, quais sejam, teoria da modernização, literatura da estabilização política, estudos sobre dependência e do corporativismo.

Apesar da delimitação estreita da literatura investigada, o autor consegue empreender análises textuais bastante significativas, uma vez que se trata dos principais discursos teóricos no contexto dos assim chamados Latin American Studies. O desenvolvimento da teoria da modernização, por exemplo, confunde-se com a própria consolidação dos Latin American Studies, ocorrido a partir dos anos 1960. O autor sustenta a idéia de que a consolidação desse campo acadêmico relacionou-se à ocorrência da Revolução Cubana, que representou para o governo americano um sinal de que a "ameaça comunista" pudesse espalhar uma onda revolucionária pela região.

Há fortes evidências que sustentam essa idéia, desde o aumento no número de universidades a oferecer cursos de Latin American Studies e de cursos desse gênero por universidade, até a parcela dos fundos destinados à pesquisa sobre a área, passando pela indispensável criação de instituições como o Commitee on Latin American Studies, em 1959, a Latin America Studies Association (LASA), em 1966, e o periódico Latin America Research Review, no mesmo ano. De fato, a proeminência dos Estados Unidos no sistema internacional havia criado uma demanda interna crescente pelo conhecimento especializado de outras regiões do mundo, que estimulou as instituições universitárias a desenvolver bastante os chamados area studies, impulsionadas pelos recursos públicos e privados de fomento à pesquisa.

É importante lembrar que esses discursos teóricos ainda tiveram profundas implicações práticas, uma vez que alguns dos seus principais representantes ocuparam cargos-chave no governo norte-americano, desde a administração John F. Kennedy até o final dos anos 1980, na gestão de Ronald Reagan. De fato, como relata Feres Júnior, há nos Estados Unidos um tradicional envolvimento da academia com o governo, representado pela participação direta desses estudiosos no processo decisório das políticas públicas, sobretudo em instituições de alguma maneira relacionadas com a política externa. É interessante acompanhar as trajetórias desses estudiosos investigadas por Feres Júnior, no decorrer dos capítulos, e perceber as relações entre os seus estudos e as políticas governamentais para a Latin America. A relação entre as idéias sobre o Outro e as políticas externas norte-americanas existe porque essas idéias produzem um conjunto de expectativas que são refletidas nas ações diante dele. Muitos dos textos produzidos no âmbito dos Latin American Studies, principalmente nos seus momentos iniciais, eram inclinados ao aconselhamento político. Essa tendência foi contrariada pela defesa do "afastamento do engajamento político em favor de um academicismo escolástico apolítico" (idem, p. 185), que em meados dos anos 1970 acompanhou a ascensão da teoria da dependência. Mesmo depois disso, porém, houve sempre exceções.

A primeira abordagem teórica tratada pelo autor é a teoria da modernização, cujo advento confunde-se com a consolidação dos Latin American Studies e com o projeto de reformar a Latin America para promover o desenvolvimento econômico. O discurso da modernização foi marcado pela presença de conceitos polissêmicos que manifestam a tradução da oposição assimétrica cultural em oposição temporal, uma vez que "é através da análise comparativa de supostos valores culturais que os cientistas sociais da modernização estabelecem a localização temporal de seu objeto: ou no campo moderno ou no tradicional" (idem, p. 281). Em um ambiente acadêmico marcado pelo paradigma da objetividade e da neutralidade científicas, percebe-se a ausência quase 
total de oposição racial explícita, até mesmo porque a sua presença poderia indicar a impossibilidade de implantar o modelo de desenvolvimento que fazia parte dos projetos norte-americanos para a região naquele momento histórico.

A literatura da estabilização política representou a manutenção do conteúdo semântico de Latin America na teoria da modernização. No entanto, o otimismo reservado foi substituído por uma visão negativa do chamado período de transição, fase em que as transformações associadas ao desenvolvimento econômico gerariam instabilidade política. A solução sugerida por essa literatura, que teve muitos de seus estudiosos envolvidos em órgão relacionados à política externa militar dos Estados Unidos, era o apoio do país a militares e elites anticomunistas da região. Apesar da ausência de inovações semânticas significativas, a literatura da estabilização política constitui terreno fértil para a investigação das relações entre os discursos teóricos e as práticas políticas, em um período em que a política externa dos Estados Unidos para a Latin America foi marcada pelo apoio às ditaduras militares que instalaram a noite em praticamente todos os países ao Sul do Rio Grande.

Os estudos da dependência, ou simplesmente a teoria da dependência, possuem um traço distintivo diante dos demais discursos analisados: trata-se de uma literatura produzida originalmente por estudiosos que, em sua maioria, eram nativos da região. O mais importante, no entanto, é a forma como os esses teóricos buscaram rejeitar a oposição assimétrica temporal, com o argumento de que países desenvolvidos e subdesenvolvidos estão integrados ao mesmo sistema capitalista internacional, o que se pode perceber na rejeição de Fernando Henrique Cardoso e Enzo Faletto à dicotomia tradicional-moderno. $\mathrm{O}$ que existe, na verdade, não é uma distância histórica entre supostas fases de desenvolvimento, mas sim um conjunto de mecanismos que tornam o desenvolvimento econômico dos países subdesenvolvidos dependente dos países centrais. Ademais, apesar de utilizarem o conceito Latin America, os dependentistas evitam defini-lo por meio de oposições assimétricas culturais; em vez disso, o problema do subdesenvolvimento é visto desde a perspectiva das variáveis econômicas estruturais.

Como o interesse do autor é pela história do conceito nos Estados Unidos, o que é analisado na verdade é a recepção da teoria da dependência nos Estados Unidos. A influência dessa perspectiva na academia norteamericana foi significativa e ocorreu entre o final dos anos 1960 e princípio dos 1970, em um contexto histórico marcado pelas críticas maciças às políticas governamentais, provenientes de movimentos sociais como a luta pelos direitos civis e o pacifismo, enquanto as políticas de direita eram cada vez mais marcadas pelo militarismo. Como anota Feres Júnior, "essa cisão ideológica se refletiu também na academia, com o aparecimento de grupos de dissidentes de orientação mais radical ou esquerdista, especialmente entre a nova geração de estudiosos diplomados nas universidades americanas durante a década de 1960" (idem, p. 180). Apesar da rejeição das formas de oposição mencionadas e da influência dos estudos da dependência nos Estados Unidos, nada disso foi suficiente para exterminar as oposições assimétricas que estruturam o campo semântico de Latin America naquele país, o que se manifestou na última literatura acadêmica analisada, os estudos do corporativismo.

O corporativismo, teoria funcionalista que se baseia na metáfora do organismo biológico para descrever a dinâmica das sociedades humanas, não traz inovações significativas ao conceito de Latin America nos Estados Unidos. De maneira extremada, os corporativistas contrapõem a Latin America à America, com o uso repetitivo de oposições culturais, temporais e raciais; sua linguagem é também marcada pelo recurso ao vocabulário patológico, como alusões a "manias", "obsessões", "parasitismos", entre outras expressões pejorativas, que sinalizam expectativas de um futuro aterrador para a região: "os Latin Americans estão irremediavelmente condenados à repetição perpétua de uma sociedade profundamente injusta, opressiva e irracional" (idem, p. 216). Como se pode ver, o corporativismo mantém a carga pejorativa associada ao conceito de Latin America no inglês norte-americano, o que está presente no discurso comum e no discurso sóciocientífico, como tantas vezes foi repetido nesta resenha.

Por fim, umas poucas palavras sobre um exercício ensaiado pelo autor no último capítulo: análise dos livros-texto sobre Latin America mais utilizados nas universidades norte-americanas. Por sua finalidade, destinados a cursos introdutórios sobre a região, essas obras precisam dialogar com noções presentes no senso comum - é uma forma de trazer o estudante, geralmente de cursos de graduação - à suposta atmosfera de Latin America. Feres Júnior consegue analisar não apenas os textos dessa literatura, mas também as próprias capas dos livros. Essas imagens, normalmente de quadros pintados por artistas da região, representam os povos 
Latin Americans como racialmente diversos, culturalmente inferiores e historicamente atrasados. É incrível como as imagens selecionadas incorporam as oposições assimétricas estruturantes do conceito nos Estados Unidos.

Em suma, o leitor encontra no livro um esforço interpretativo de resultados bastante interessantes, que dão a A história do conceito de Latin America nos Estados Unidos um final leve e prazeroso de ser lido. Isto sem deixar de lado a crítica às formas de desrespeito ao Outro.

Daniel Jatobá (djatoba@iuperj.br) é Mestre em Relações Internacionais pela Universidade de Brasília (UnB) e doutorando em Ciência Política no Instituto Universitário de Pesquisas do Rio de Janeiro (Iuperj).

\section{REFERÊNCIAS BIBLIOGRÁFICAS}

DÖPCKE, W. 2001. Apogeu e colapso do sistema internacional europeu (1871-1918). In : SARAIVA, J. F. S. (org.). Relações Internacionais - dois séculos de história : entre a preponderância européia e a emergência americano-soviética (1815-1947). Brasília : Instituto Brasileiro de Relações Internacionais.

FERES JÚNIOR, J. 2005. A história do conceito de "Latin America” nos Estados Unidos. Bauru : USC.

HONNETH, A. 1995. The Struggle for Recognition : The Moral Grammar of Social Conflicts. Cambridge, UK: Polity.

KOSELLECK, R. 1985 [1979]. Futures Past : On the Semantics of Historical Time. Cambridge, Mass. : Massachusetts Institute of Technology.

TAYLOR, C. 1994. The Politics of Recognition. In : GUTMAN, A. (org.). Multiculturalism : Examining the Politics of Recognition. Princeton : Princeton University. 